\title{
Wave-driven flow over shallow reefs
}

\author{
Graham Symonds \\ Department of Geography and Oceanography, University College, Australian Defence Force Academy \\ University of New South Wales, Canberra, Australian Capital Territory, Australia
}

Kerry P. Black

Victorian Institute of Marine Sciences, East Melbourne, Victoria, Australia

Ian R. Young

Department of Civil and Maritime Engineering, University College, Australian Defence Force Academy University of New South Wales, Canberra, Australian Capital Territory, Australia

\begin{abstract}
Long-term (1 month) observations of waves and currents over a natural reef are presented which show a strong correlation between offshore rms incident wave height and cross-reef currents at subtidal frequencies. The energy spectrum of the cross-reef currents shows a significant peak at twice the semidiurnal tidal frequency, while the spectrum of sea surface elevation over the reef flat shows no corresponding peak. Furthermore, experimental results reported by Gourlay (1993) show setup over the reef occurs in the absence of a beach, and the cross-reef transport decreases with an increase in the sea surface slope across the reef flat due to an increase in setup at the top of the reef face. Analytic solutions for flow forced by wave breaking over an idealized reef explain the above features of cross-reef flows in the absence of a beach. Through the surf zone on the reef face the cross-reef gradient in the radiation stress due to wave breaking is partitioned between balancing an offshore preșsure gradient associated with setup over the reef and forcing a mean flow across the reef. Over the reef flat, where the depth is constant, there is no forcing due to wave breaking and the flow is driven by a pressure gradient which results from the setup through the surf zone. The magnitude of the setup through the surf zone is such that the transport across the reef flat matches the transport through the surf zone which is forced by the gradient in the radiation stress. Solutions are presented for general reef geometry, defined by the reef width and slope of the seaward reef face, and incident wave forcing, defined by the depth at the breakpoint and the depth of water over the reef. As the depth over the reef goes to zero, the solutions converge to the plane beach solutions described by Longuet-Higgins and Stewart (1964), wave setup is maximized, and the cross-reef transport is zero. In other cases the relative magnitudes of the setup and the cross-reef transport depend on the geometry of the reef and the incident wave forcing.
\end{abstract}

\section{Introduction}

Shallow, submerged reefs subject to significant wave action are common throughout the Pacific and Indian Oceans. The region of the Great Barrier Reef in Australia stretches for $1600 \mathrm{~km}$ covering an area of $230,000 \mathrm{~km}^{2}$ [Maxwell, 1968]. Estimates of the total number of reefs vary between 2500 and 3000 with an average area of $6.9 \mathrm{~km}^{2}$ and a total reef area of $20,055 \mathrm{~km}^{2}$ [Hopley et al., 1989]. The tidal range varies considerably throughout the reef with an average range of approximately $3 \mathrm{~m}$. The reefs may be exposed at low spring tides, while at high tide the maximum water depth may be a few meters. Such reefs often surround lagoons and low atolls and provide protection from incident waves by dissipating the wave energy through the surf zone on the seaward side of the reef. Wave-induced setup and currents due to wave breaking over the reef could therefore Copyright 1995 by the American Geophysical Union.

Paper number 94JC02736. 0148-0227/95/94JC-02736\$05.00 have a significant impact on the circulation and flushing of the lagoon [Black and Hatton, 1990]. Hearn and Parker [1988] have shown that currents at subtidal frequencies in a deep channel behind Ningaloo Reef in Western Australia were highly correlated with the offshore rms wave height. They estimated a volumetric flushing time between 5 and 23 hours.

Wave setup over coral reefs has been reported by Tait [1972], Jensen [1991], and Gourlay [1993] and has been explained using the concept of radiation stress introduced by Longuet-Higgins and Stewart [1964]. The gradient in the radiation stress through the surf zone over the reef is balanced by an offshore pressure gradient analogous to the plane beach solution described by Longuet-Higgins and Stewart [1964] and Bowen et al. [1968]. However, this mechanism cannot account for a downstream return to still water level which could be expected for a reef in an otherwise unbounded ocean. Alternatively, it has been suggested that a pressure gradient develops to balance the high friction usually associated with flow over shallow reefs, the 


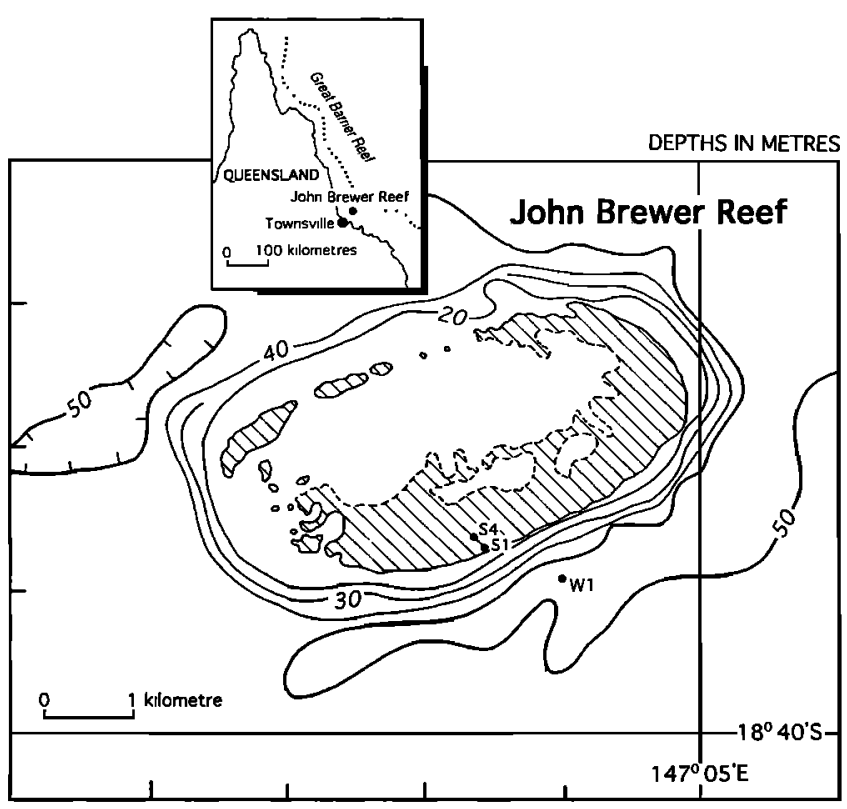

Figure 1. Location of John Brewer Reef and the instrument sites used in this study. Wave rider buoy (W1), surface-piercing wave staff (S1), and current meter (S4) are shown.

pressure gradient increasing as the current speed increases. In this case the mechanism driving the current and the initial increase in sea level is not accounted for. A complete theoretical treatment is needed which includes wave forcing over the reef incorporating both pressure gradients and currents and allows sea level to return to a "still" water level at a sufficient distance either side of the reef. In the limit as the depth over the reef goes to zero, the solutions should approach the well-known setup on a beach. In this paper we present a theoretical framework over an idealized reef which includes these features of the solutions.

Long-term observations of wave-driven flow over a shallow reef have not been reported previously, and in the next section we present some observations demonstrating features of the flow in this regime which have not been described elsewhere. We present some unique long-term observations of flow over a natural reef and discuss some interesting laboratory results reported by Gourlay [1993]. The theoretical model is described in section 3, followed by results in section 4 which provide an explanation of the unusual features of the observations and valuable insight into the dynamics of wave-driven flow over submerged reefs. Discussion and conclusions follow in sections 5 and 6 , respectively.

\section{Observations}

In 1988 a unique measurement program was carried out on John Brewer Reef located approximately $70 \mathrm{~km}$ northeast of Townsville, Queensland (see Figure 1). The experiment was designed to investigate wave attenuation and transformation across an exposed offshore reef and involved an array of surface-piercing wave staffs, current meters, and wave rider buoys. The instrument array and observations of wave attenuation and transformation have been reported by Hardy et al. [1990] and Hardy [1993]. The experimental program ran for approximately 1 month, providing a unique opportunity to examine the variability in wave-driven, cross-reef currents due to tidal variations in sea level and wave height variations associated with passing weather systems. Only those instruments relevant to our particular application are shown in Figure 1. An offshore wave rider buoy was located $500 \mathrm{~m}$ seaward of the reef edge at a depth of $50 \mathrm{~m}$ (site W1 in Figure 1). The wave rider had a sampling rate of $2.56 \mathrm{~Hz}$ and recorded 2048 points (approximately $13 \mathrm{~min}$ ) every hour throughout the experiment. Sea surface elevation was measured at the seaward edge of the reef flat at site S1 using a wave staff based on the technique described by $Z$ warts [1974] with an estimated mean water level accuracy of $1 \mathrm{~cm}$. The wave staff had a sampling rate of $4 \mathrm{~Hz}$ recorded for 20 min every 2 hours for most of the experiment. An InterOcean Systems, Inc., S4 current meter, located at site S4 approximately $150 \mathrm{~m}$ from the reef edge, recorded 1 -min averages of velocity at 10 -min intervals for the period August 13 to September 23, 1988.

In Figure 2 are shown the low-pass-filtered cross reef currents at site S4 and the corresponding low-pass-filtered rms wave heights from the wave rider at W1. A Chebyshev type I low-pass filter with a half-power point at 0.04 cycles per hour was used to remove the tidal component from the observed currents. The data clearly show that the cross-reef currents at subtidal frequencies are highly correlated with the offshore rms wave height. For convenience, positive cross-reef currents here are directed into the lagoon. The two periods of negative or offshore directed currents over the reef are associated with very low waves. The corresponding correlation coefficient is 0.92 , demonstrating a strong linear relationship between offshore wave height and cross-reef currents. The along-reef currents were found to be poorly correlated with offshore wave height.

The power spectrum of the unfiltered cross-reef currents is shown in Figure 3. The spectral estimates were obtained from 10 segments with 512 points per segment, giving 20 degrees of freedom. The $95 \%$ confidence interval is shown on the figure. The largest peak in the spectrum appears at the semidiurnal tidal frequency $(0.082 \mathrm{cph})$, yet a second significant peak occurs at twice the semidiurnal frequency $(0.164$

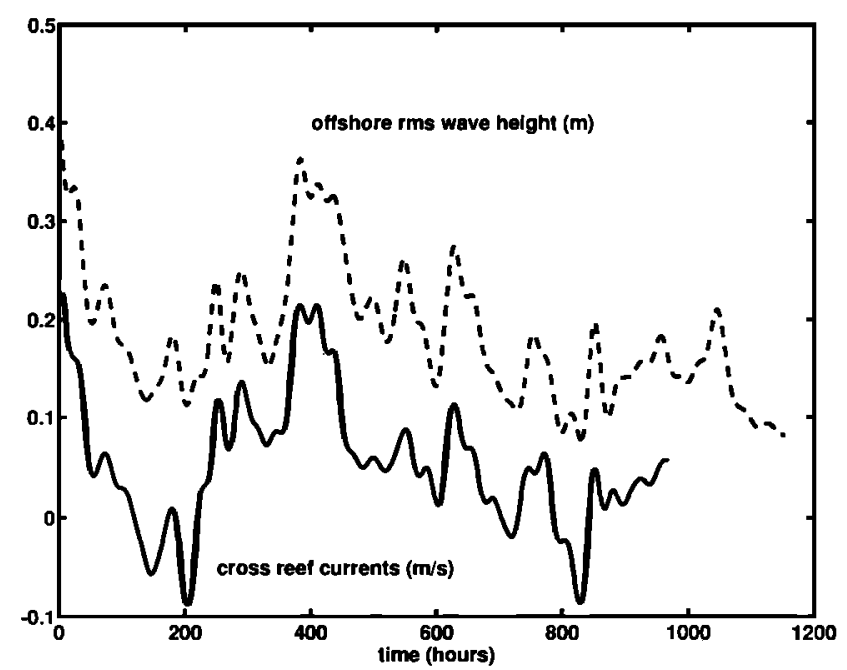

Figure 2. Filtered cross-reef currents (solid line) measured at site $\mathrm{S} 4$ and rms wave height (dashed line) at W1. 
cph). The corresponding spectrum of sea surface elevation does not contain a peak at $0.164 \mathrm{cph}$ but does show significant tidal peaks. Higher harmonics of the major tidal constituents have been attributed to nonlinear distortion of the tidal wave in shallow water [Uncles, 1981; Speer and Aubrey, 1985]. Friedrichs and Aubrey [1988] document "overtides" along the east coast of North America and show the magnitude of the harmonics is typically at least an order of magnitude smaller than the major tidal constituent. Harmonic analysis of tidal records in the vicinity of John Brewer Reef [Gay et al., 1991] also reveal small but significant contributions from overtides but are almost an order of magnitude smaller than the major $\mathbf{M}_{2}$ tidal constituent. While overtides may contribute to the energy at harmonics of the tidal constituents, in the following sections we propose an additional mechanism, unrelated to shallow water, nonlinear tidal distortion, which causes the wave-driven, cross-reef currents to be modulated at twice the tidal frequency while the sea surface elevation over the reef flat is not modulated.

Laboratory experiments reported by Gourlay [1993] also reveal interesting features of wave-driven flow over a submerged reef. A wave tank was partitioned into three sections connected at both ends with an idealized reef in the center section. Since the sections were connected, the water level on either side of the reef was maintained at still water level. Gourlay [1993] investigated the wave setup and cross-reef currents generated by waves breaking on the reef face as a function of incident wave height and still water depth over the reef. The experimental results show that as the depth over the reef decreases, the setup increases and the crossreef transport decreases. However, since the water level at the downstream end of the reef is maintained at the constant still water level, increasing the setup over the reef would increase the sea surface slope across the reef flat. Therefore the results suggest that the cross-reef transport is decreasing in the presence of an increasing sea surface slope across the reef flat. Gourlay [1993] does not discuss this feature of his observations.

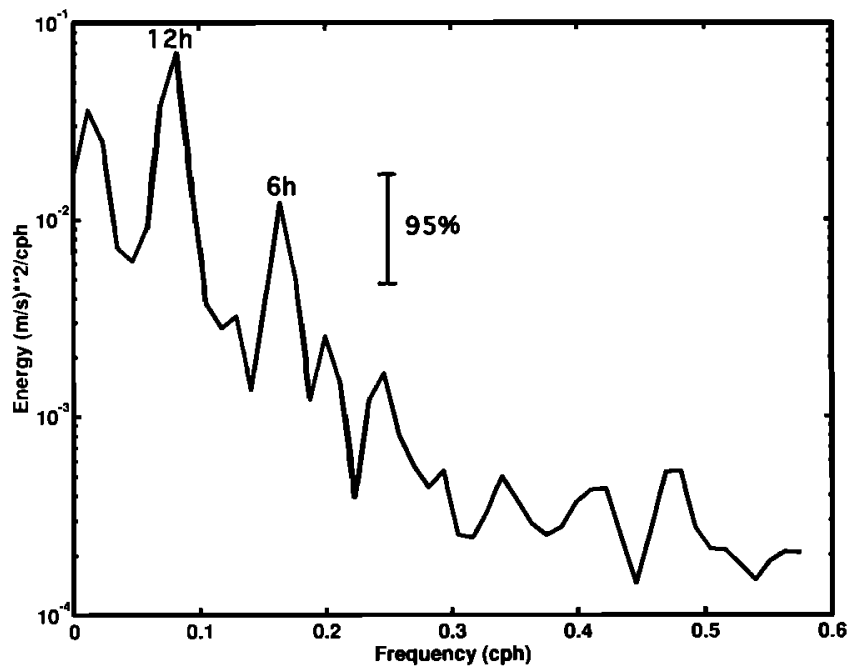

Figure 3. Power spectrum of the unfiltered cross-reef currents measured at site S4 on John Brewer Reef. The corresponding periods, in hours, are shown above the two significant peaks.

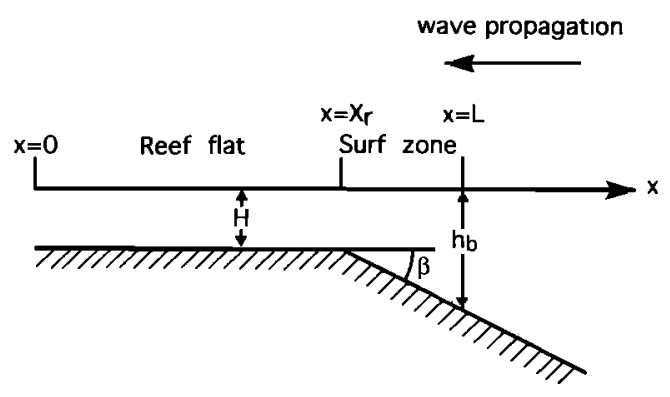

Figure 4. Schematic reef defining the parameters used in the theoretical model.

\section{Theory}

A schematic of an idealized reef is shown in Figure 4. We assume the top of the reef is flat, while on the seaward face of the reef the depth $h$ is given by

$$
h=\left(x-X_{r}\right) \tan \beta+H \quad x>X_{r}
$$

where $\beta$ is the bottom slope, $H$ is the depth over the reef, and $x$ is positive seaward. The width of the reef flat is $X_{r}$ and uniform, normally incident waves break at $x=L$ where the depth is $h_{b}$.

On a natural beach, wave setup is explained in terms of a balance between an offshore pressure gradient and the onshore gradient of the onshore radiation stress which can be written as

$$
g \frac{\partial \zeta}{\partial x}=-\frac{1}{\rho h} \frac{\partial S_{x x}}{\partial x}
$$

where $\zeta$ is the sea surface elevation; $g$, the gravitational acceleration; $\rho$, the density; and $S_{x x}$ the $x$ component of the $x$-directed radiation stress which, in shallow water, is given approximately by

$$
S_{x x}=\frac{3}{2} E
$$

where $E$ is the incident wave energy given by

$$
E=\frac{1}{2} \rho g a^{2}
$$

and $a$ is the incident wave amplitude. Through the surf zone the incident wave amplitude is assumed to remain a constant proportion of the depth such that

$$
a=\gamma h
$$

where $\gamma$ is a constant. Equation (5) has been widely used in modeling wave height decay through the surf zone since the early work by Longuet-Higgins and Stewart [1964], Bowen et al. [1968], and Bowen [1969]. Furthermore, (5) has been shown to be a good approximation for monochromatic waves in the laboratory [Bowen et al., 1968] and on a natural beach with random waves where the wave amplitude is replaced with the root-mean-square wave height [Thornton and Guza, 1982, 1983]. A recent application is given by Thornton and Kim [1993]. On beaches the constant of proportionality is in the range 0.3-0.5. On John Brewer Reef, site $\mathrm{S} 1$ was the only site which was always within the surf zone. At this site, Hardy et al. [1990] estimate $\gamma=0.35$. Using (5), (2) then becomes 


$$
g \frac{\partial \zeta}{\partial x}=-\frac{3}{2} g \gamma^{2} \tan \beta
$$

If we truncate the top of the beach as shown in Figure 4, the radiation stress forcing may also accelerate a cross-reef current and the steady momentum balance, assuming linear friction, becomes

$$
g \frac{\partial \zeta}{\partial x}=-\frac{1}{\rho h} \frac{\partial S_{x x}}{\partial x}-\frac{r u}{h}
$$

where $u$ is the depth-integrated velocity and $r$ is a constant friction coefficient, while continuity gives

$$
\frac{\partial(h u)}{\partial x}=0
$$

The use of linear friction allows analytic solutions of (7) and (8) which, in the appropriate limits, are shown to converge to the well-known solutions for setup on a plane beach, described theoretically by Longuet-Higgins and Stewart [1964] and Bowen et al. [1968] and experimentally by Guza and Thornton [1981], Holman and Sallenger [1985], and Nielsen [1988], all of which show a shoreward increase in sea surface elevation through the surf zone, the magnitude increasing with increasing offshore wave height. Linear friction has also been widely used in modeling mean flow in the nearshore [Thornton and Kim, 1993; $\dot{W} u$ et al., 1985; Mei and Liu, 1977; Noda, 1974; Bowen, 1969]. Typically, $r \approx c_{f} u_{w}$ where $u_{w}$ is the wave orbital velocity and the friction factor $c_{f}$ is of order 0.01 [Longuet-Higgins, 1970]. Over coral reefs, observations suggest friction coefficients are significantly higher [Black and Hatton, 1990], though in our application, the magnitude of the friction coefficient does not significantly alter the main features of the solutions.

In this paper we solve (7) and (8) subject to the boundary conditions

$$
\begin{array}{ll}
\zeta=0 & x=0 \\
\zeta \rightarrow 0 & x \rightarrow \infty
\end{array}
$$

To nondimensionialize (7) and (8), we scale the offshore distance by the width of the surf zone and the depth by the depth at the breakpoint where the incident waves first break. The sea surface elevation is scaled by the setup predicted for a plane beach with the same slope and surf zone width as our idealized reef. The velocity is then scaled according to (7) with $\partial \zeta / \partial x=0$. Nondimensional variables denoted by asterisks are then defined as follows

$$
\begin{gathered}
x^{*}=\frac{x}{L-X_{r}} \\
h^{*}=h / h_{b} \\
\zeta^{*}=\frac{\zeta}{\frac{3}{2} \gamma^{2}\left(L-X_{r}\right) \tan \beta} \\
u^{*}=\frac{u}{\frac{3}{2} g \gamma^{2} \tan \beta \frac{H}{r}}
\end{gathered}
$$

This choice of scaling allows us to easily compare our solutions with the corresponding solutions on a plane beach. Seaward of the surf zone, the wave amplitude increases toward the shore which, on a plane beach, leads to a small set down toward the breakpoint [Longuet-Higgins and Stewart, 1964]. For our purposes we will ignore the effects of wave shoaling and assume the radiation stress forcing is zero seaward of the breakpoint. Through the surf zone the wave amplitude decreases according to (5), and the radiation stress forcing term has the form shown on the right-hand side of (6). Across the reef top, since the depth is constant, the wave amplitude is also constant and the radiation stress forcing is again zero. After scaling, the momentum equation becomes for reef flat (region 1)

$$
\frac{d \zeta^{*}}{d x^{*}}+\frac{R_{1} u^{*}}{h^{*}}=0 \quad 0 \leq x^{*} \leq \frac{R_{2}}{1-R_{2}}
$$

for surf zone (region 2)

$$
\frac{d \zeta^{*}}{d x^{*}}+\frac{R_{1} u^{*}}{h^{*}}=-1 \quad \frac{R_{2}}{1-R_{2}} \leq x^{*} \leq \frac{1}{1-R_{2}}
$$

and for seaward region (region 3)

$$
\frac{d \zeta^{*}}{d x^{*}}+\frac{R_{1} u^{*}}{h^{*}}=0 \quad x^{*}>\frac{1}{1-R_{2}}
$$

The continuity equation becomes

$$
\frac{d\left(h^{*} u^{*}\right)}{d x^{*}}=0
$$

where $R_{1}=H / h_{b}$ and $R_{2}=X_{r} / L$. Solutions in the three regions defined in (11a)-(11c) are obtained as follows.

In region 1 the depth is constant and $h^{*}=R_{1}$. Using (11a) and (12), the equation for $\zeta^{*}$ is simply

$$
d^{2} \zeta^{*} / d x^{* 2}=0
$$

The solution is then given by

$$
\begin{gathered}
\zeta^{*}=C_{1}+C_{2} x^{*} \\
u^{*}=-C_{2}
\end{gathered}
$$

where $C_{1}$ and $C_{2}$ are constants to be determined.

In region 2 the nondimensional depth, using (1), becomes

$$
h^{*}=\left(x^{*}-\frac{R_{2}}{1-R_{2}}\right)\left(1-R_{1}\right)+R_{1}
$$

Using (12) and eliminating $u$ from (11b) the equation for $\zeta^{*}$ becomes

$$
h^{*} \frac{d^{2} \zeta^{*}}{d x^{* 2}}+2\left(1-R_{1}\right) \frac{d \zeta^{*}}{d x^{*}}=-2\left(1-R_{1}\right)
$$

If we let $e^{t}=h^{*}\left(x^{*}\right)$, then changing variables in (17) yields

$$
\frac{d^{2} \zeta^{*}}{d t^{2}}+\frac{d \zeta^{*}}{d t}=-\frac{2 e^{t}}{1-R_{1}}
$$

The solution for $\zeta^{*}$ is then given by 


$$
\zeta^{*}=C_{3}+C_{4} e^{-t}-\frac{e^{t}}{1-R_{1}}
$$

which can be written

$$
\zeta^{*}=C_{3}+\frac{C_{4}}{h^{*}}-\frac{h^{*}}{1-R_{1}}
$$

where $C_{3}$ and $C_{4}$ are constants. Using (11b), the solution for $u^{*}$ is given by

$$
u^{*}=\frac{C_{4}\left(1-R_{1}\right)}{R_{1} h^{*}}
$$

In region 3 the equation for $\zeta^{*}$ is the homogeneous form of (18), and the solution is given by

$$
\zeta^{*}=C_{5}+C_{6} / h^{*}
$$

and the velocity is given by

$$
u^{*}=\frac{C_{6}\left(1-R_{1}\right)}{R_{1} h^{*}}
$$

The integration constants $C_{i}$ are obtained by applying the boundary conditions

$$
\begin{array}{ll}
\zeta^{*}=0 & x^{*}=0 \\
\zeta^{*} \rightarrow 0 & x^{*} \rightarrow \infty
\end{array}
$$

and the additional matching conditions that $\zeta^{*}$ and $u^{*}$ be continuous at $x^{*}=R_{2} /\left(1-R_{2}\right)$ and $x^{*}=1 /\left(1-R_{2}\right)$ where $h^{*}$ equals $R_{1}$ and 1 , respectively. Under these conditions the constants are given by

$$
\begin{gathered}
C_{1}=0 \\
C_{2}=\frac{\left(1-R_{1}\right)\left(1-R_{2}\right)}{\left(1-R_{2}\right) R_{1}+\left(1-R_{1}\right) R_{2}} \\
C_{3}=\frac{1}{1-R_{1}} \\
C_{4}=-\left[\frac{1}{R_{1}}+\frac{\left(1-R_{1}\right) R_{2}}{R_{1}^{2}\left(1-R_{2}\right)}\right]^{-1} \\
C_{5}=0 \\
C_{6}=C_{4}
\end{gathered}
$$

An important consequence of using linear friction in (7) is that the nondimensional sea surface elevation given by (14), (20), and (22) is independent of the friction coefficient $r$ which only affects the velocity through the scaling in (10d).

The two ratios $R_{1}$ and $R_{2}$ represent the geometry of the reef and the magnitude of the forcing, and both vary between 0 and 1. $R_{1}$ is the ratio of the depth over the reef flat to the depth at the breakpoint. The limit as the depth over the reef flat vanishes $\left(R_{1} \rightarrow 0\right)$ corresponds to the plane beach case, and the cross-reef transport must vanish while the setup approaches the plane beach solution. Alternatively, as the depth over the reef flat approaches the depth at the breakpoint $\left(R_{1} \rightarrow 1\right)$, the waves would cease to break and there would be no forcing and hence no setup or cross-reef transport. $R_{2}$ is the ratio of the reef width $X_{r}$ to the breakpoint position $L$, which are relative to the origin defined as the point where sea level returns to the still water level. The reef width $X_{r}$ is defined as the distance, on the reef flat, over which sea level returns to the still water level which may not be equal to the physical width which is often difficult to define on a natural reef. The case when $R_{2}$ tends to 0 corresponds to a narrow reef, while the case when $R_{2}$ tends to 1 corresponds to an infinitely wide reef. Here we examine the limiting solutions as $R_{1}$ and $R_{2}$ approach 0 and 1. We consider the solution at the seaward edge of the reef flat where $x^{*}=R_{2} /\left(1-R_{2}\right)$ and $h^{*}=R_{1}$, and the sea surface elevation and cross-reef current are given by

$$
\zeta^{*}=\frac{C_{2} R_{2}}{1-R_{2}}
$$

and

$$
u^{*}=-C_{2}
$$

\subsection{Case $0<R_{2}<1$}

As $R_{1}$ tends to 0 , using (25b), $C_{2} \rightarrow\left(1-R_{2}\right) / R_{2}$, and the solutions approach the following limits

$$
\zeta^{*} \rightarrow 1
$$

and

$$
h^{*} u^{*} \rightarrow 0
$$

In this case the depth over the reef is small compared to the depth at the breakpoint, and most of the incident wave energy is dissipated through the surf zone. The solutions converge to the plane beach solutions where the cross-shore transport is zero and the sea surface elevation approaches the predicted setup on a plane beach.

In the limit as $R_{1}$ tends to $1, C_{2} \rightarrow 0$, and we have

$$
\zeta^{*} \rightarrow 0
$$

and

$$
h^{*} u^{*} \rightarrow 0
$$

In this limit the depth over the reef approaches the depth at the breakpoint. The waves do not break so there is no forcing, and the setup and cross-reef transport are 0.

\subsection{Case $0<R_{1}<1$}

In the limit as $R_{2} \rightarrow 0, C_{2} \rightarrow\left(1-R_{1}\right) / R_{1}$, and we have

$$
\zeta^{*} \rightarrow 0
$$

and

$$
h^{*} u^{*} \rightarrow-\left(1-R_{1}\right)
$$

In this case the reef is narrow compared to the width of the surf zone. The radiation stress forcing goes entirely into driving the cross-reef flow. In this limit the sea surface elevation at the breakpoint, where $x^{*}=1 /\left(1-R_{2}\right)$ and $h^{*}=1$, is given by

$$
\zeta^{*} \rightarrow-R_{1}
$$

The significance of the set down seaward of the surf zone is discussed later. 

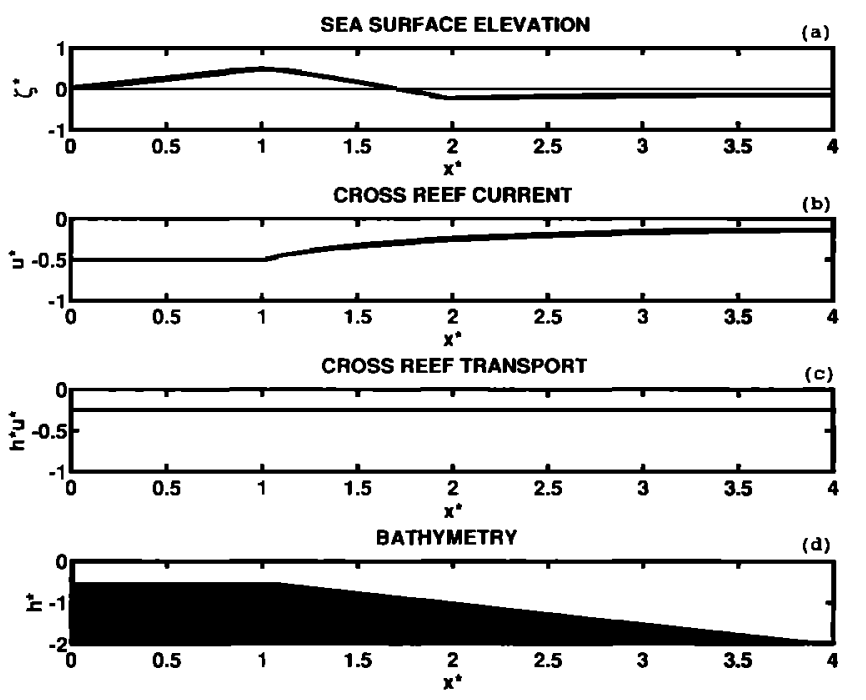

Figure 5. Nondimensional solutions for (a) sea surface elevation and (b) current and (c) transport for the case $R_{1}=$ $\boldsymbol{R}_{2}=0.5$ as functions of the nondimensional offshore distance $x^{*}$, and (d) reef bathymetry. The surf zone is between $x^{*}=1$ and $x^{*}=2$.

As $R_{2}$ approaches 1, using (25b) and (26) we have, at $x^{*}=$ $R_{2} /\left(1-R_{2}\right)$

$$
\zeta^{*} \rightarrow 1
$$

and, using (27)

$$
h^{*} u^{*} \rightarrow 0
$$

In this case the reef is very wide compared to the width of the surf zone. For a given forcing the pressure gradient across the reef flat becomes very small and the solutions converge to the plane beach case.

The case $R_{1}=R_{2}=0$ corresponds to a plane beach, and a singularity occurs in $u^{*}$ since the boundary condition at $x^{*}=0$ given in (9) is no longer appropriate. However, in this limit the transport $h^{*} u^{*}$ remains finite since $h^{*}$ vanishes. In the following section we present results over the full range of values of $R_{1}$ and $R_{2}$ between 0 and 1 .

\section{Results}

Solutions for the case $R_{1}=R_{2}=0.5$ are shown in Figure 5 as functions of the nondimensional offshore distance $x^{*}$. The bathymetry is shown in Figure 5d, and the surf zone is defined by the region between $x^{*}=1$ and $x^{*}=2$. The gradient in the radiation stress through the surf zone accelerates a current up the slope and produces a setup (see Figure 5a) at the seaward edge of the reef flat. The resulting pressure gradient across the reef flat forces a cross-reef flow to match the transport through the surf zone. Seaward of the surf zone, there is a corresponding set down to produce a pressure gradient such that the transport $h^{*} u^{*}$ is constant across the model domain $\left(0<x^{*}<\infty\right)$ as shown in Figure 5c. As mentioned in the previous section, the nondimensional setup over the reef is independent of friction.

Solutions for the nondimensional sea surface elevation (Figure 6a) and the nondimensional cross-reef transport
(Figure 6b) are shown at $x=X_{r}$ as a function of $R_{1}$ and $R_{2}$. These results illustrate the limiting cases discussed in the previous section and reveal some of the characteristics observed in the data. For example, for a given $R_{2}$ the cross-reef transport in the negative $x$ direction (Figure 6b) increases as $R_{1}$ increases from zero while the sea surface elevation (Figure 6a), and consequently, the cross-reef sea surface slope, decreases which is consistent with the laboratory results of Gourlay [1993]. However, as $R_{1}$ continues to increase, the cross-reef transport goes through a maximum and then decreases with a continuing decrease in the sea surface elevation and cross-reef pressure gradient.

Shown in Figure 7 is the nondimensional sea surface elevation at $x=L$ which is quite different than the results shown in Figure 6a at $x=X_{r}$. For a given $R_{2}$, proportionally more set down occurs seaward of the surf zone as $R_{1}$ increases, while the relative setup at the inner edge of the surf zone decreases (see Figure 6a).

\subsection{Variation Over a Tidal Cycle}

On any given reef the geometry remains fixed, yet $R_{1}$ and $R_{2}$ may change as the depth over the reef varies through a tidal cycle. To gain some insight as to what happens on a reef with a given width $X_{r}$ and slope $\tan \beta$, we have fixed the breakpoint depth $h_{b}$ for a given incident wave height and varied $R_{1}$ by changing the depth over the reef. As $R_{1}$ varies, the width of the surf zone varies, and $R_{2}$ is given by

$$
R_{2}=\frac{X_{r} \tan \beta}{h_{b}\left(1-R_{1}\right)+X_{r} \tan \beta}
$$

Solutions for a range of breakpoint depths are shown in Figure 8. As $h_{b}$ increases, the nondimensional setup at $x=$ $X_{r}$, the seaward edge of the reef flat, decreases (Figure 8a) while the cross-reef transport increases (Figure 8b). Proportionally more of the incident wave momentum goes into driving the cross-reef transport as the incident wave amplitude increases and, correspondingly, less momentum is accounted for by the pressure gradient through the surf zone. For a given $h_{b}$ the nondimensional setup at the
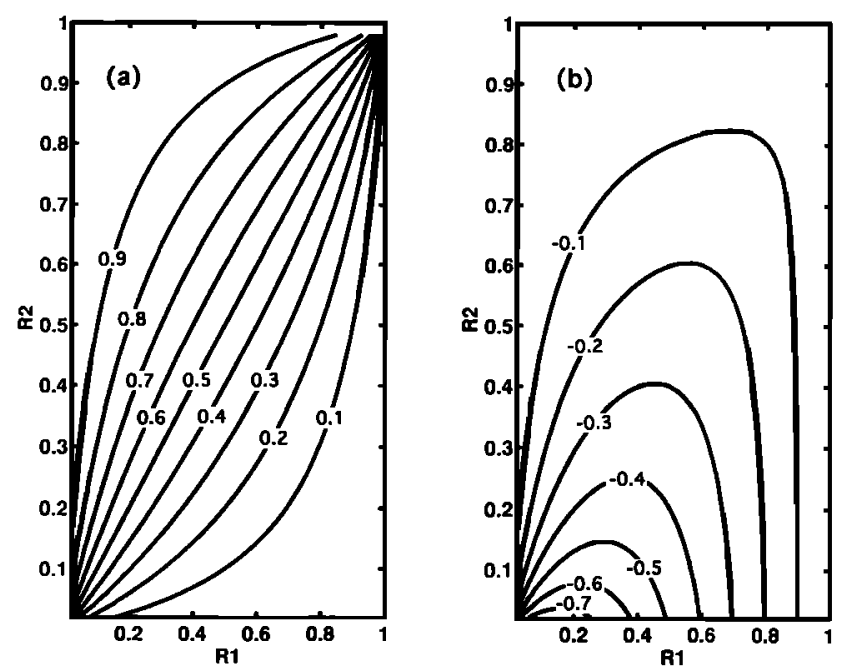

Figure 6. Nondimensional solutions at the seaward edge of the reef flat where $x=X_{r}$; (a) sea surface elevation and (b) cross-reef transport. 
seaward edge of the reef flat increases with decreasing depth over the reef (decreasing $R_{1}$ ) converging to the plane beach solution $\left(\zeta^{*}=1\right)$ as the depth goes to zero. At this limit the cross-reef transport is also zero.

When $R_{1}<0.5$, the setup decreases with increasing depth over the reef (increasing $R_{1}$ ) while the cross-reef transport increases, consistent with the observations reported by Gourlay [1993]. Using (11a), the cross-reef transport over the reef flat is given by $h^{*} u^{*}=-h^{*} \partial \zeta^{*} / \partial x^{*}$, the product of the depth and the sea surface slope over the reef flat. As $R_{1}$ increases, the setup decreases (see Figure 8a), and so the sea surface slope over the reef flat will also decrease. When $R_{1}<0.5$ for a given $h_{b}$, the cross-reef transport (Figure 8b) is dominated by changes in $h^{*}$; as $h^{*}$ increases (increasing $R_{1}$ ), the transport increases while the pressure gradient decreases, as observed by Gourlay [1993].

For $R_{1}>0.5$ the transport is dominated by changes in the sea surface slope, which decreases as the setup decreases with increasing $R_{1}$, approaching 0 again as $R_{1}$ approaches 1 and the depth over the reef approaches $h_{b}$. A consequence of the solutions shown in Figure $8 b$ is that it is possible for the cross-reef transport to go through a maximum during each half of the tidal cycle if at low tide, $R_{1}<0.5$ and at high tide, $R_{1}>0.5$. In this case the wave-driven transport and currents can oscillate at twice the tidal frequency, providing an explanation for the 6-hour peak in the spectrum shown in Figure 3. The corresponding sea surface elevation over the reef flat increases monotonically with decreasing water depth and so will not be modulated at twice the tidal frequency.

\subsection{Set Down Seaward of the Surf Zone}

Set down occurs seaward of the surf zone (Figure 7) but is not associated with wave shoaling as described by LonguetHiggins and Stewart [1964] since we have assumed the wave

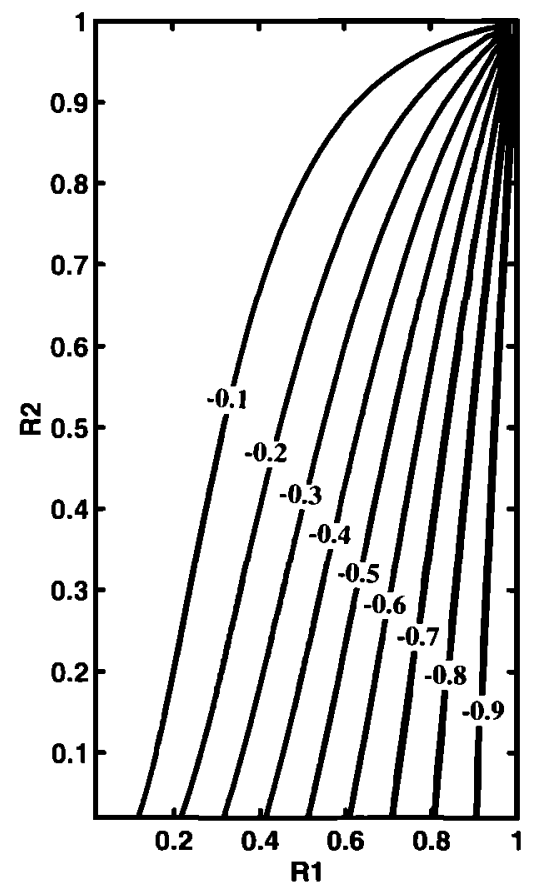

Figure 7. Nondimensional sea surface elevation at the breakpoint where $x=L$.
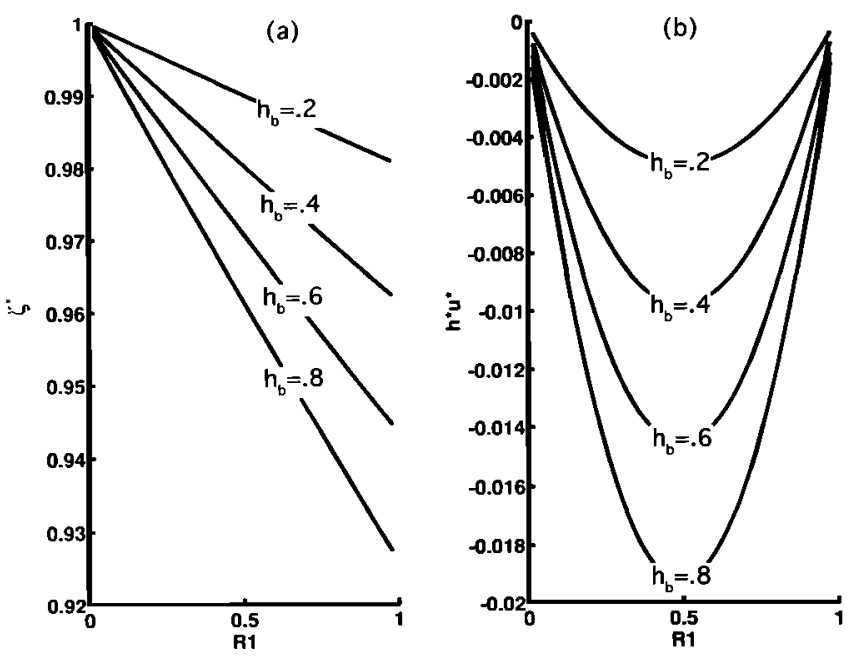

Figure 8. Nondimensional solutions at the seaward edge of the reef flat $\left(x=X_{r}\right)$ for specific breakpoint depths in meters as shown on each curve, (a) sea surface elevation and (b) cross-reef transport. $X_{r}=100 \mathrm{~m}$, and $\tan \beta=0.1$.

height is constant offshore. The set down shown in Figure 7 occurs to produce a pressure gradient driven transport offshore to match the transport through the surf zone. The magnitude of this set down therefore depends on the magnitude of the transport. In the discussion of the limiting cases we saw the transport across the reef flat goes to 0 as $R_{2}$ approaches 1 (see Figure 6b), the case where the reef is very wide compared to the surf zone width. When $h_{b}$ and $\tan \beta$ are constant and the width of the reef decreases, proportionally more set down occurs at the seaward edge of the surf zone (Figure 9a) while the cross-reef transport increases (Figure 9b).

Since the set down is associated with the cross-reef transport, we would expect to see a maximum at an intermediate value of $R_{1}$, corresponding to the maximum in cross-reef transport, and zero set-down as $R_{1}$ approaches 0 and 1. This is not apparent in the nondimensional results shown in Figure 9a, where the set down increases with increasing $R_{1}$. However, the sea surface elevation has been normalized by the plane beach setup which also vanishes as $R_{1}$ approaches 1 (see Figure 6a), and the nondimensional sea surface elevation seaward of the surf zone is given by the ratio of two small numbers. To demonstrate this, the results shown in Figure 9a have been dimensionalized using 10 with $h_{b}=1 \mathrm{~m}$ and $\tan \beta=0.1$. The results are plotted in Figure 10 , where $R_{1}$ has been replaced with $H$ since the breakpoint depth is kept constant. As expected, the set-down is maximized at an intermediate depth corresponding to the maximum in the cross-reef transport. While the sea surface elevation over the reef flat is not modulated at twice the tidal frequency, such a modulation might be expected seaward of the surf zone though the magnitude of the set down is expected to be only a few centimeters (as shown in Figure 10).

\subsection{Model Versus Observations}

A direct comparison between the observed currents, shown in Figure 2, and the model predictions can be made by using the observed offshore wave height and mean depths over the reef to estimate the forcing parameter $R_{1}$. We have 

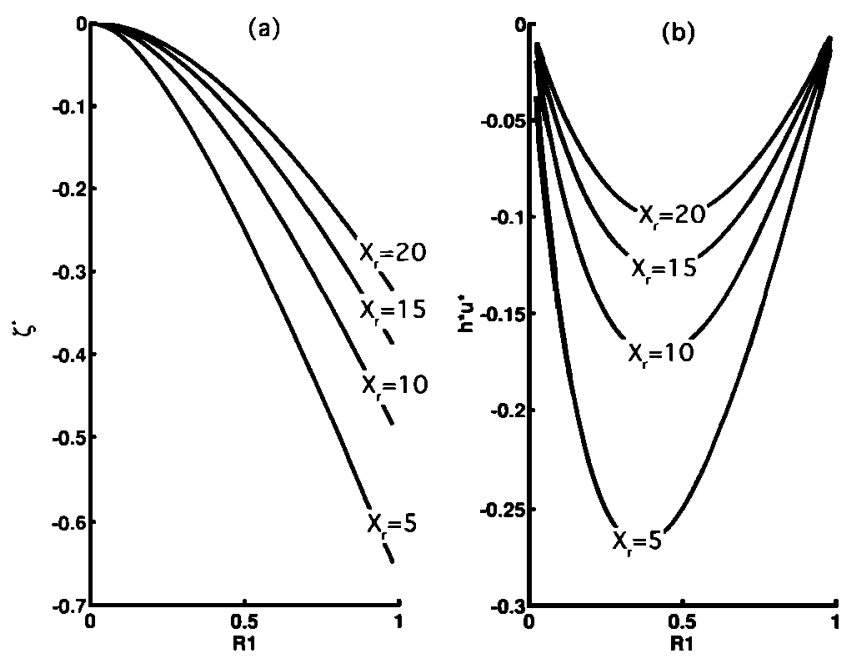

Figure 9. Nondimensional solutions at the breakpoint ( $x=$ $L)$ for specific reef widths $X_{r}$ in meters as shown on each curve, (a) sea surface elevation and (b) cross-reef transport. Results obtained using $h_{b}=1 \mathrm{~m}$ and $\tan \beta=0.1$.

used linear shoaling theory to estimate the wave height just outside the surf zone using the observed wave height offshore and then estimated the breakpoint depth $h_{b}$ using (5). The mean water depth over the reef was obtained at two hourly intervals using the sea level records at site S1 (Figure 1) and low-pass filtered as before to remove the tidal components. Using these data, a time series of the forcing parameter $R_{1}$ was calculated. The parameter $R_{2}$ is given by (37) where we have used $\tan \beta=0.1$ corresponding to the measured slope at the top of the reef face [Hardy, 1993]. The reef width parameter $X_{r}$ and the friction coefficient $r$ are then adjusted to obtain the best fit between the model and the observed currents.

A comparison of the low-pass-filtered observed and model-derived currents is shown in Figure 11. Note the observed currents are plotted in the model coordinate frame with $x$ positive offshore. Also, the time series are shorter than the

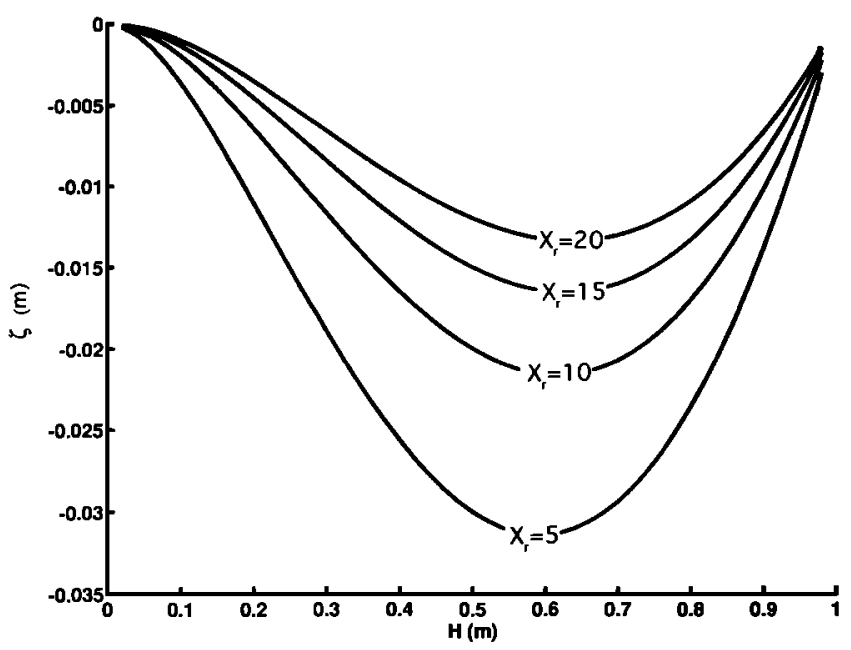

Figure 10. Dimensional sea surface elevation at the breakpoint as a function of depth over the reef flat $\boldsymbol{H}$ for different reef widths $X_{r}$, as shown in meters on each curve. Results obtained using $h_{b}=1 \mathrm{~m}$, and $\tan \beta=0.1$.

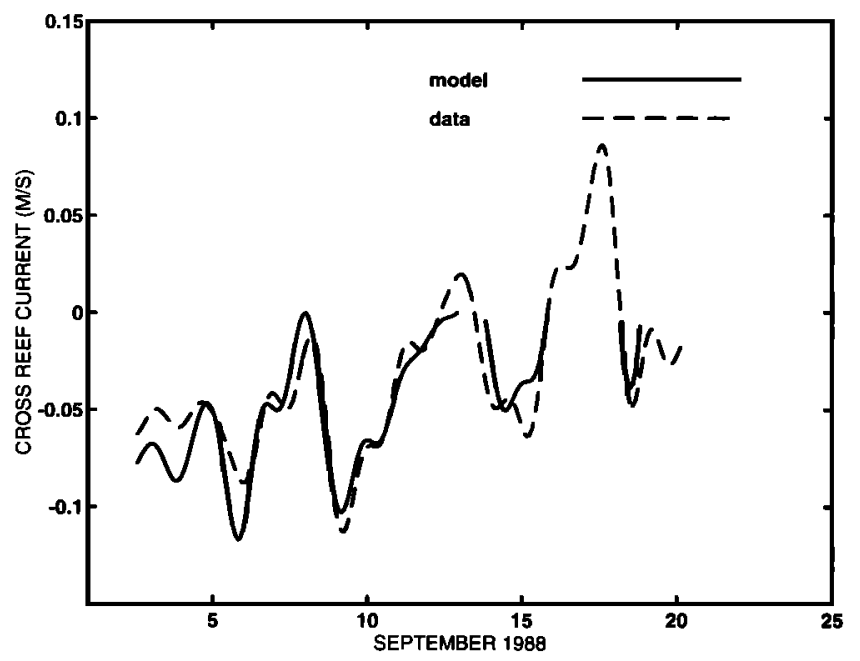

Figure 11. Low-pass-filtered observed currents (dashed line) and model-derived currents (solid line) with $X_{r}=300$ $\mathrm{m}$ and $r=0.25$.

data shown in Figure 2 because the time series of sea level data are shorter. The gaps in the model results correspond to low wave conditions when according to the criterion expressed in (5), the waves were not breaking and the model currents are zero. At these times the observed currents are directed offshore and are not associated with wave breaking over the reef.

While there is remarkably good agreement between the observed and model-derived currents, the fit is not unique in that a similar result can be obtained by suitably changing $X_{r}$ and $r$. For example, increasing $X_{r}$ to $500 \mathrm{~m}$ with a corresponding decrease in $r$ to 0.1 produces a similar fit to the one shown in Figure 11. In this latter case, if the setup at the edge of the reef flat is of order $10 \mathrm{~cm}$, then the sea surface slope across the reef flat would be of order $2 \times 10^{-4}$ which is too small to resolve in the present data. Furthermore, high friction factors over reefs have been reported previously, and considerable uncertainty exists over actual values which will probably vary from site to site. The values for $X_{r}$ and $r$ used here are, at best, order of magnitude estimates. Regardless of the actual parameter values used, the agreement between model and observations is very good, particularly since current variability over these timescales is also associated with other processes such as wind forcing and coastaltrapped waves. It is beyond the scope of this paper to examine these other processes.

\section{Discussion}

Through the surf zone over a shallow reef the wave momentum lost through breaking is balanced by an offshore directed pressure gradient and a cross-reef flow. The results in the previous section demonstrate how the momentum is partitioned between the pressure gradient and cross-reef flow as a function of the ratios $R_{1}$ and $R_{2}$. On the reef flat the magnitude of the cross-reef transport depends on the pressure gradient across the reef which is determined by the setup at the seaward edge of the reef flat and the reef width. Increasing the pressure gradient across the reef must result in a corresponding increase in the offshore directed pressure 

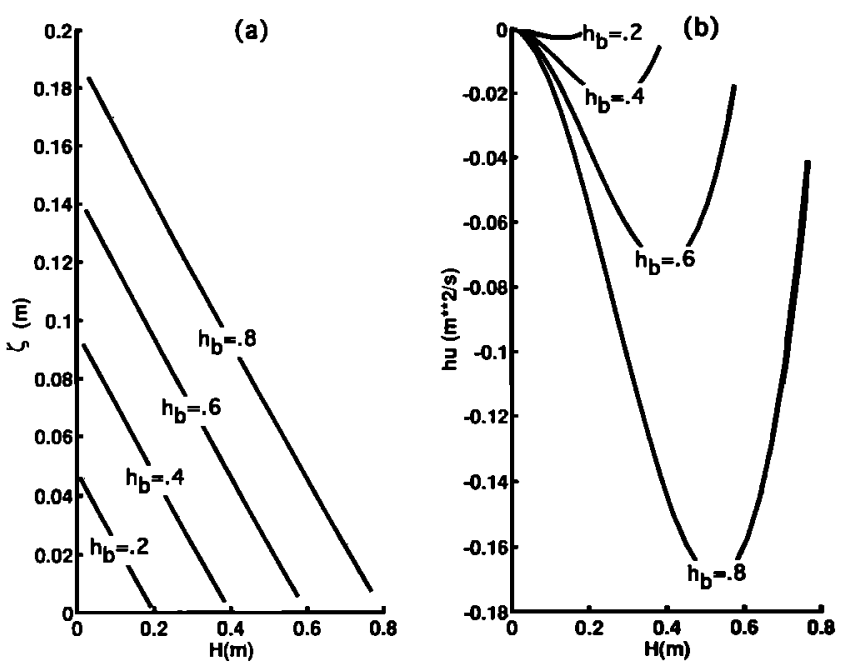

Figure 12. Dimensional equivalent of the solutions shown in Figure 8 at the seaward edge of the reef flat $\left(x=X_{r}\right)$ for specific breakpoint depths in meters as shown on each curve, (a) sea surface elevation and (b) cross-reef transport. $X_{r}=100 \mathrm{~m}$ and $\tan \beta=0.1$.

gradient through the surf zone which opposes the radiation stress gradient. This results in a proportional decrease in the wave-driven transport through the surf zone and ultimately limits the maximum setup, which occurs when the cross-reef transport is zero. This process determines the partition of momentum between the cross-reef transport and waveinduced setup through the surf zone. The maximum achievable setup is equivalent to the plane beach solution. In this case the momentum lost through wave breaking is entirely balanced by the pressure gradient through the surf zone and none goes into driving a current across the reef.

The nondimenisionalization in (10) allows us to readily compare the theoretical results presented here with wellknown plane beach solutions. The discussion in the previous section demonstrates that the model presented here is consistent with established theory which is shown to be an asymptotic solution of our model. To examine the solutions for a specific reef and forcing requires dimensionalizing using (10). For example, dimensional results corresponding to Figure 8 are shown in Figure 12 for the case $X_{r}=100 \mathrm{~m}$ and $\tan \beta=0.1$. In this case, solutions for a given breakpoint depth $h_{b}$ are calculated and the parameter $R_{1}$ is replaced by the depth over the reef $H$. As in Figure 8, the different curves correspond to the breakpoint depths as shown. As $h_{b}$ increases, the setup increases (Figure 12a). For a given $h_{b}$, as the depth over the reef flat increases, the setup decreases (Figure 12a). As the depth over the reef approaches zero, the setup approaches the plane beach setup which can be calculated using (6). The depth over the reef flat at which the cross-reef transport (Figure 12b) is a maximum increases as the breakpoint depth, and hence the incident wave height increases. Therefore on a given reef the stage of the tide at which maximum wave-driven cross-reef transport occurs depends on the incident wave height. Furthermore, if we assume an average transport of $0.1 \mathrm{~m}^{2} \mathrm{~s}^{-1}$ over a reef $5 \mathrm{~km}$ long, then the volume transported across the reef in 1 day would be approximately $4 \times 10^{7} \mathrm{~m}^{3}$. This would be equivalent in volume to a lagoon $5 \mathrm{~km}$ long by $2 \mathrm{~km}$ wide and $4 \mathrm{~m}$ deep, which is consistent with many natural coral reefs. Hearn and Parker [1988] estimated a mean cross-reef transport of $0.18 \mathrm{~m}^{2} \mathrm{~s}^{-1}$ for a section of Ningaloo Reef in Western Australia and estimated volumetric flushing times of the lagoons from 5 to 23 hours. These estimates suggest that wave-driven flows may provide an efficient mechanism for flushing coral reef lagoons.

\section{Conclusions}

This paper examines the wave-driven component of crossreef flows. The linear model agrees remarkably well with the observations and, more importantly, demonstrates how the relative magnitudes of the currents and setup depend on the geometry of the reef and the magnitude of the forcing. The choice of scaling demonstrates that well-known solutions for a plane beach can be obtained as asymptotic solutions of the model presented here. Furthermore, the model provides an explanation of the following and previously unreported features of cross-reef flows from laboratory and field studies: (1) a strong correlation between offshore wave height and cross-reef currents at timescales greater than a day; (2) a modulation of the cross-reef currents at twice the tidal frequency while sea surface elevation over the reef is not modulated; and (3) a decrease in cross-reef flow associated with an increase in the sea surface slope across the reef flat.

In addition to explaining the above observations, the model also predicts a modulation of sea surface elevation seaward of the surf zone at twice the tidal frequency, while a similar modulation is not predicted over the reef flat. Tidal analysis of currents and sea level over a reef subjected to significant incident wave action could therefore produce spurious results due to these wave-forced effects. The model also predicts set down seaward of the surf zone which is not associated with wave shoaling. This set down occurs to provide a pressure gradient offshore to maintain a transport to match the cross-reef flow resulting from wave breaking through the surf zone.

Acknowledgments. The authors would like to thank R. Gorman for programming support. Salary support for $K$. P. Black and $R$. Gorman was provided by a grant from the Australian Research Council under the Small Grants Scheme. The John Brewer Reef data were provided by Tom Hardy of James Cook University. His assistance is gratefully acknowledged.

\section{References}

Black, K. P., and D. Hatton, Dispersal of larvae, pollutants and nutrients on the Great Barrier Reef, at scales of individual reefs and reef groups, in 2 and 3 dimensions, report, $77 \mathrm{pp}$., Great Barrier Reef Marine Park Auth., Townsville, Queensland, 1990.

Bowen, A. J., Rip currents, 1, Theoretical investigations, J. Geophys. Res., 74, 5467-5478, 1969.

Bowen, A. J., D. L. Inman, and V.P. Simmons, Wave set-down and setup, J. Geophys. Res., 73, 2569-2577, 1968.

Friedrichs, C. T., and D. G. Aubrey, Nonlinear tidal distortion in shallow, well-mixed estuaries: A synthesis, Estuarine Coastal Shelf Sci., 27, 521-545, 1988.

Gay, S. L., J. C. Andrews, and K. P. Black, Dispersal of neutrally buoyant material near John Brewer Reef, in Acanthaster and the Coral Reef: A Theoretical Perspective, Lecture Notes Biomath., edited by R. H. Bradbury, pp. 95-119, Springer-Verlag, New York, 1991.

Gourlay, M. R., Wave setup and wave generated currents on coral reefs, 11th Australas. Conf. on Coastal and Ocean Engineering, 
Conf. Pübl. 93/4, pp. 479-484, Inst. of Eng., Canberra, Aust. Capital Territory, 1993.

Guza, R. T., and E. B. Thornton, Wave set-up on a natural beach, J. Geophys. Res., 86, 4133-4137, 1981.

Hardy, T. A., The attenuation and spectral transformation of wind waves on a coral reef, Ph.D. thesis, 336 pp., James Cook Univ., Townsville, Queensland, 1993.

Hardy, T. A., I. R. Young, R. C. Nelson, and M. R. Gourlay, Wave attenuation on an offshore coral reef, in Proceedings of 22nd International Coastal Engineering Conference, vol. 1, pp. 330344, American Society of Civil Engineers, New York, 1990.

Hearn, C. J., and I. N. Parker, Hydrodynamic processes on the Ningaloo Reef, Western Australia, Proc. Int. Symp. Coral Reefs $6 t h, 2,497-502,1988$.

Holman, $R$, and $A$. Sallenger, Setup and swash on a natural beach, J. Geophys. Res., 90, 945-953, 1985.

Hopley, D., K. E. Parnell, and P. J. Isdale, The Great Barrier Reef Marine Park: Dimensions and regional patterns, Aust. Geogr. Stud., 27, 47-66, 1989.

Jensen, O. J., Waves on coral reefs, in Coastal Zone '91: Proceedings of the Seventh Symposium on Coastal and Ocean Management, Long Beach, California, pp. 2668-2680, American Society of Civil Engineers, New York, 1991.

Longuet-Higgins, M. S., Longshore currents generated by obliquely incident sea waves, 2, J. Geophys. Res., 75, 6790-6801, 1970.

Longuet-Higgins, M. S., and R. W. Stewart, Radiation stresses in water waves; a physical discussion, with applications, Deep Sea Res., 11, 529-562, 1964.

Maxwell, W. G. H., Atlas of the Great Barrier Reef, 258 pp., Elsevier, New York, 1968.

Mei, C. C., and P. L.-F. Liu, Effects of topography on the circulation in and near the surf zone-linear theory, Estuarine Coastal Mar. Sci., 5, 25-37, 1977.

Nielsen, P., Wave set-up: A field study, J. Geophys. Res., 93, $15,643-15,652,1988$.
Noda, E. K., Wave-induced nearshore circulation, J. Geophys. Res., 79, 4097-4106, 1974.

Speer, P. E., and D. G. Aubrey, A study of non-linear tidal propagation in shallow inlet/estuarine systems, Part II, Theory, Estuarine Coastal Shelf Sci., 21, 207-224, 1985.

Tait, R. J., Wave setup on coral reefs, J. Geophys. Res., 77, 2207-2211, 1972.

Thornton, E. B., and R. T. Guza, Energy saturation and phase speeds measured on a natural beach, J. Geophys. Res., 87, 9499-9508, 1982.

Thornton, E. B., and R. T. Guza, Transformation of wave height distribution, J. Geophys. Res., 88, 5925-5938, 1983.

Thornton, E. B., and C. S. Kim, Longshore current and wave height modulation at tidal frequency inside the surf zone, $J$. Geophys. Res., 98, 16,509-16,519, 1993.

Uncles, R. J., A note on tidal asymmetry in the Severn Estuary, Estuarine Coastal Shelf Sci., 13, 419-432, 1981.

Wu, C-S., E. B. Thornton, and R. T. Guza, Waves and longshore currents: Comparison of a numerical model with field data, $J$. Geophys. Res., 90, 4951-4958, 1985.

Zwarts, C. M. G., Transmission line wave height transducer, in Proceedings of International Symposium on Ocean Wave Measurement and Analysis, New Orleans, vol. 1, pp. 605-620, American Society of Civil Engineers, New York, 1974.

K. P. Black, Victorian Institute of Marine Sciences, 23 St. Andrews Place, East Melbourne, Victoria 3002, Australia.

G. Symonds, Department of Geography and Oceanography, University College, Australian Defence Force Academy, University of New South Wales, Canberra, A. C. T. 2600, Australia.

I. R. Young, Department of Civil and Maritime Engineering, University College, Australian Defence Force Academy, University of New South Wales, Canberra, A. C. T. 2600, Australia.

(Received November 15, 1993; revised October 18, 1994; accepted October 18, 1994.) 